\title{
DETECTING COASTAL URBANIZATION AND LAND USE CHANGE IN SOUTHERN TURKEY
}

\author{
Hakan ALPHAN, Laden GÜVENSOY \\ Department of Landscape Architecture, Cukurova University, \\ Balcali Campus, 01330, Adana, Turkey
}

Submitted 03 Jun. 2015; accepted 26 Oct. 2015

\begin{abstract}
One of the most important needs in contemporary landscape planning is quantitative land use/land cover (LU/LC) change information. The reason a strong emphasis is placed on landscape change information is that it serves as an ecological and geographical basis for preparing and implementing development plans in a more sustainable manner. Multi-temporal analysis of LU/LC changes on the Eastern Mediterranean coast of Turkey revealed that there is a marked preference for these areas primarily for building development. This paper demonstrates a methodology that relies on quantitative analysis techniques for assessing spatiotemporal changes in LU/LC in the case of the eastern Mediterranean coast of Turkey. In this respect, satellite image datasets (SPOT panchromatic, Landsat TM) acquired in 1989, 1995, 2001 and 2007 were enhanced. Resulting images were classified and compared to detect coastal urbanization and development trends. Post-classification change analyses were employed to quantify land cover conversions in three periods from 1985 to 1995, from 1995 to 2001 and from 2001 to 2007. This paper demonstrated that urban, agriculture and shrublands changed rapidly in this part of the Mediterranean coast.
\end{abstract}

Keywords: urbanization, coastal development, Mediterranean, land use, change detection.

\section{Introduction}

Urbanization in coastal regions is complex since rapid building development in these areas is generally driven by various land uses. Most often, residential development, industries and transportation appear as major forces that create changes. Change detection of urban land use/land cover (LU/LC) is one of the most extensively studied topics in landscape monitoring (Ramachandra et al. 2014; Yu et al. 2013; Xian et al. 2012; Sancar et al. 2009; Ayazli et al. 2010). Utility and importance of urban LU/LC change detection based on multi-temporal remotely sensed imagery is widely accepted (Stefanov et al. 2001; Kamh et al. 2012; Schneider 2012). This importance arises from the fact that LU/LC information can be used as an indicator for understanding human interactions in the environment and for assessing implications of change trends on current and future states of ecosystem health and functioning (e.g., Desalegn et al. 2014). Urbanization has serious impacts on economic development (Walker 2001). It also affects biogeochemical processes (Zhang et al. 2014) and causes environmental pollution (Fang et al. 2014).

Since urbanization interferes with many ecological systems and processes, geospatial information on its implications is essential for land use planning and management.

Various techniques and datasets have been used for mapping urban land cover and its change. Techniques based on image radiometry provide satisfactory results in classifying urban land cover and detecting related change phenomena. In this respect, multi-resolution segmentation and object based classifiers have been proven to be useful (Smiraglia et al. 2014). Sub-pixel image analysis methods and the hybrid approaches that combine pixeland object-based classifications help to increase the efficiency of urban land cover mapping procedures (Yang et al. 2003; Villa et al. 2012). Change vector analysis and data mining of dense time stacks may be given as examples of change detection approaches that have been reported to be useful for conceptualizing urban change ( $\mathrm{He}$ et al. 2011; Schneider 2012).

Many of the urban LU/LC change studies use medium-resolution images such as Landsat (Alberti et al. 2004) or SPOT (Chang et al. 2010) multispectral images. Combinations of images acquired by different aerial and/ or satellite sensors (e.g., Landsat TM/ETM+ and Terra/ ASTER) are also frequently used (Kamh et al. 2012;

Corresponding author: Hakan Alphan

E-mail: alphan@cu.edu.tr 
Merlotto et al. 2012). Spatial and spectral characteristics of these images are generally satisfactory for urban studies. However, depending on the extent, spatial configuration and history of the development, older images with higher spatial and spectral characteristics may sometimes be necessary. In such cases, merging these image datasets (Kamh et al. 2012; Deng et al. 2005) is useful as it leads to spatially enhanced images. The main advantage of this approach is to provide images with increased spatial and spectral capabilities that allow easier and more accurate classification and mapping. Several authors adopted this approach as an image enhancement procedure using multispectral and panchromatic images from the same remote sensing platform such as SPOT (Shaban, Dikshit 2002) or IRS (Ahmad, Singh 2002). Several other authors also merged SPOT with Landsat images (Nunez et al. 1998, 1999; Zhou et al. 1998; Hosomura, Katho 1998; Aiazzi et al. 1996; Chavez et al. 1991; Wu et al. 2004)

As summarized above, urban development attracts attention as it is an important environmental indicator, which can be taken into consideration in environmental planning and management processes (Alphan, Sonmez 2015; Hepcan 2013; Salvati, Sabbi 2011; Miralles i Garcia 2007; Prem 2007). Datasets and analysis protocols for analyses are dependent upon both planning needs and landscape characteristics. Data type and change analysis procedures for use in a fragmented and/or rapidly changing landscape may differ from those to be used in a homogenous and more stable landscape. Detecting changes in landscapes of spatial and temporal heterogeneity require higher spatial detail and frequent observations (Kowe et al. 2015; Liu, Yang 2015; Taubenbock et al. 2012; Yiran et al. 2012).

Urbanization on the eastern Mediterranean coast of Turkey has occurred rapidly and it created serious environmental implications such as water pollution and destruction of agricultural areas.

Residential building development is an important phenomenon along the coast. This is mostly driven by tourism- and recreation-related reasons that have created very dense vertical development of large multi-storey buildings since 1980s (Alphan, Sonmez 2015). This part of the Turkish Mediterranean coast is highly accessible by highways from populated Mediterranean and Southeast Anatolian cities such as Adana, Kahramanmaraş and Gaziantep. As being one of the closest and easily accessible sea coasts to above mentioned centres, study area has attracted domestic tourism, which resulted with development of large apartment blocks used as summer apartments.

The fact that building development takes place on fertile agricultural lands is one of the most important environmental concerns. Therefore, mapping and monitoring of these trends hold a potential to demonstrate spatial behaviour of development, which may be considered as a key input for suitability analyses (e.g., suitability of land areas for building development) and land use change modelling (e.g., CA Markov Model). This information is critically important for development plans that aim to achieve an optimum spatial organization for coastal land uses.

The aim of this study is to analyse LU/LC change trends in the west of Mersin, one of the most rapidly developing coastal zones in the Mediterranean region of Turkey. In this respect, digital image enhancement and interpretation techniques were employed in order to demonstrate change processes and provide qualitative and quantitative information for development planning.

\section{Materials and methods}

\subsection{Study area}

The study area is situated in the west of the city of Mersin, a populated urban centre in the Eastern Mediterranean region of Turkey (Fig. 1). Typical Mediterranean climate with dry summers and mild winters prevail in the region. Agriculture and residential development are the most prominent land uses. The area has experienced various environmental problems due to development of multi-storey buildings serving as summer apartments (Alphan, Derse 2013). Most of these buildings occupy a narrow coastal strip that was transformed from prime agricultural areas during the last three decades.

\subsection{Data sets}

The history of the urbanization and the biophysical characteristics of landscapes in study area make it necessary to work over a long time span with the images of high spatial resolution. For this reason, satellite image datasets (SPOT panchromatic and Landsat TM) acquired in a time span between 1989 and 2007 were used for image classification and change detection. As a commercial highresolution optical imaging Earth observation satellite system that operates from space, SPOT is short for Satellite Pour l'Observation de la Terre (Satellite for observation of Earth). SPOT program was initiated by the French space agency in the 1970s (CNES-Centre National d'Études Spatiales). Panchromatic and multispectral instruments on board the SPOT satellites have been acquiring highresolution images of Earth since February 1986, following the launch of the SPOT 1 satellite (10 m Panchromatic, 20 $\mathrm{m}$ multispectral). SPOT datasets are particularly important for change studies that date back to 1980's and that require high spatial resolution.

The Landsat Program is the longest running project that aims to acquire satellite images of the Earth's surface. Several instruments (RBV, MSS, TM) carried by Landsat satellites 1-5 have provided images of the Earth. Landsat 
7 and 8 that carry ETM+ and OLI instruments are still operational. Millions of images acquired by these instruments are a unique resource for global change research and applications in agriculture, cartography, geology, forestry and regional planning. The fact that, on April 21, 2008, the USGS announced plans to provide all archived Landsat scenes at no charge to all users makes Landsat datasets even more important for change studies.

Combined use of these image datasets for analysis in landscapes of high spatial and temporal diversity has a potential to provide increased spatial and spectral capabilities. For this reason, four SPOT panchromatic and four near-anniversary Landsat TM datasets were selected for data fusion. Acquisition dates of these images are 1987 (December), 1995 (May/June), 2001 (May, June) and 2007 (September/November). Change analyses that employ spectral band comparisons (e.g., image ratioing) on bitemporal basis require images of the same season in order to avoid false interpretations during comparisons. However, post-classification approaches are not dependent upon seasonal consistency since images of the earlier and later dates are classified separately. Considering different season of image acquisitions, post-classification classification was performed.

\subsection{Image fusion}

LU/LC mapping procedures based on panchromatic imagery sometimes require enhancement operations such as data fusion in order to create images with higher quality and more information. In this approach, the main idea arises from the fact that panchromatic images have much finer resolution than do the multispectral images. Therefore, panchromatic and multispectral images from the same or different platforms are merged to convey more information on the resulting image. Several methods have been developed for this purpose. Commonly used methods include red-green-blue (RGB) to intensity-huesaturation (HIS) (e.g., Welch, Ehlers 1987), principal components analysis (PCA) (e.g., Chavez et al. 1991) and Wavelet (e.g., Wu et al. 2004) transformation techniques. Sarp (2014) reported that PCA provides the highest spectral quality among other techniques such as IHS, GrammSchmidt and Brovey transformations.

SPOT panchromatic images with 10-meter spatial resolution are greyscale images covering visible proportion of the electromagnetic spectrum. These images provide information on visual variables such as size, shape, hue, texture, orientation, etc. Higher spatial resolution of panchromatic images has its advantages for object identification in terms of several variables such as size, shape and texture. However, limited spectral information contained in these datasets generally requires pre-processing for image enhancement. Image fusion combines relevant information (e.g. spectral and spatial information) from geo-referenced input images into a single image.

Since image fusion requires datasets with high spatial consistency, image datasets in this study were geometrically corrected and registered to UTM projection. During

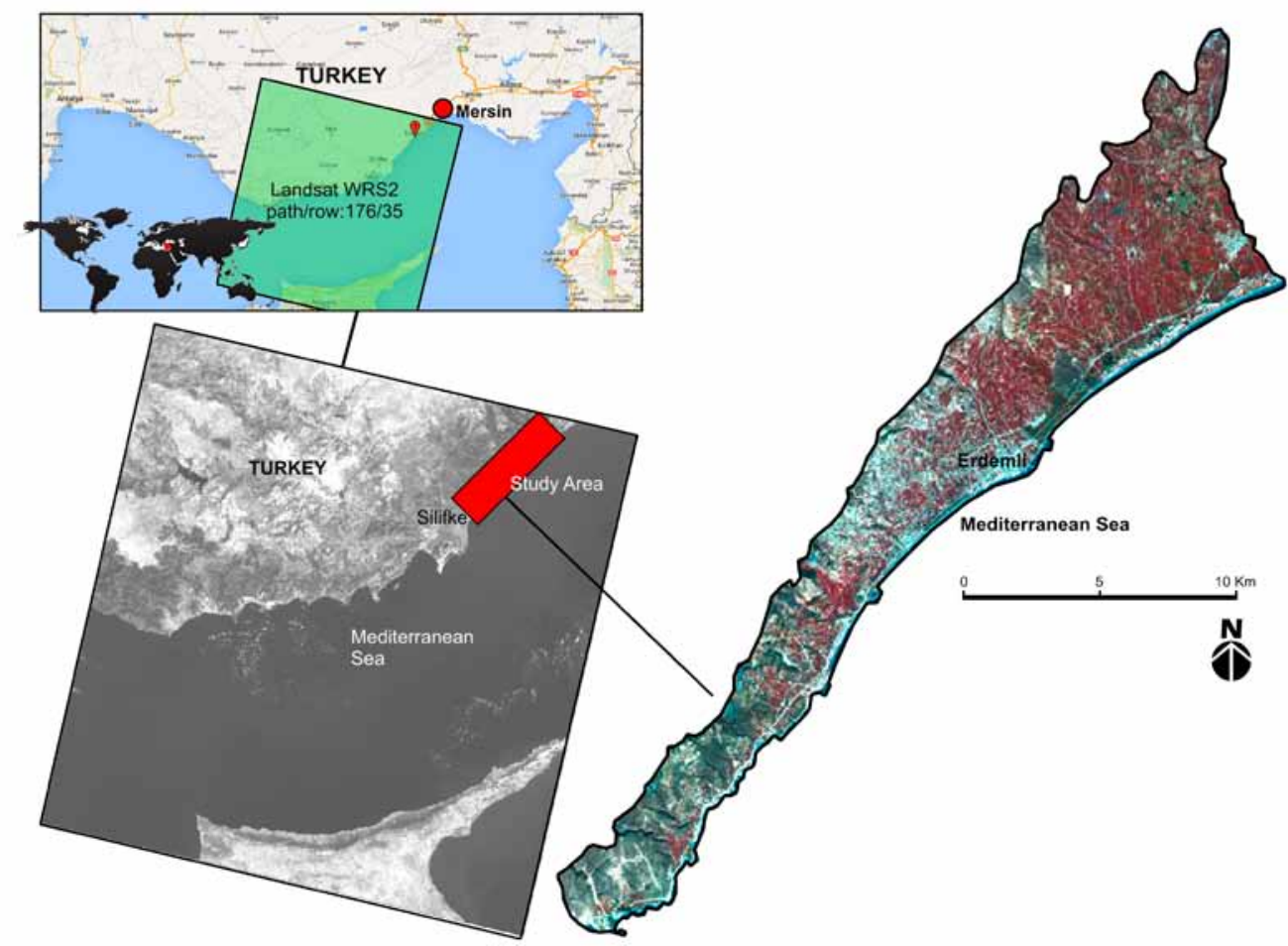

Fig. 1. Location of the study area 
this process, resampling was done with RMS errors less than one pixel to obtain high spatial consistency.

Principal components merge were used for spatial enhancement. In this process it is assumed that the first principal component (PC) contains only overall scene luminance; all inter-band variation is contained in the other five PCs, and scene luminance in the short wave infrared (SWIR) bands is identical to visible scene luminance (Erdas 1999). Examples of high resolution panchromatic and multispectral input images and the results of this operation are given in Figure 2.

As shown in Figure 2, data merging operation substantially increased spatial quality of images. This is particularly important for discriminating small and scattered building patches from surrounding environment and for identifying agricultural patches, which can be confused with other land cover features such as vegetated (i.e. shrubland) or non-vegetated (i.e. bare areas) natural areas in input images.

\subsection{Object-based image classifications}

An object-based methodology was adopted for image classification. According to this methodology, image segmentation and classification were performed for each of the images of 1989, 1995, 2001 and 2007.

Segmentation is a process that groups adjacent pixels of a homogeneous spectral similarity. Specifically, during this process a watershed delineation approach is employed to partition input imagery based on their variance. A derived variance image is treated as a surface image allocating pixels to particular segments based on variance similarity. Across space and over all input bands, a moving window assesses this similarity and segments are defined according to a stated similarity threshold. Various similarity tolerances and other factors (e.g. weight mean and variance) were experimented to produce most representative segmentation results. During segmentation, a 3x3 window size was used. Weight mean and variance factors were 0.3 . A similarity tolerance of 20 was set during this procedure

Segments can then be classified using a majority rule classifier based on a majority class within a segment (Eastman 2012). Thematic classifications were based on segmentation results. Sets of training segments were created for each of the dates in order to define spectral signatures prior to Maximum Likelihood classification. The classified maps were validated and compared on a bitemporal basis. Post-classification change analyses were employed to quantify land cover conversions in three periods from 1985 to 1995 , from 1995 to 2001 and from 2001 to 2007.

During segmentation and classification, "Segmentation" and "Segclass" modules of Idrisi 17.0 (The Selva Edition) was used. Flow of the classification procedure is given in Figure 3.
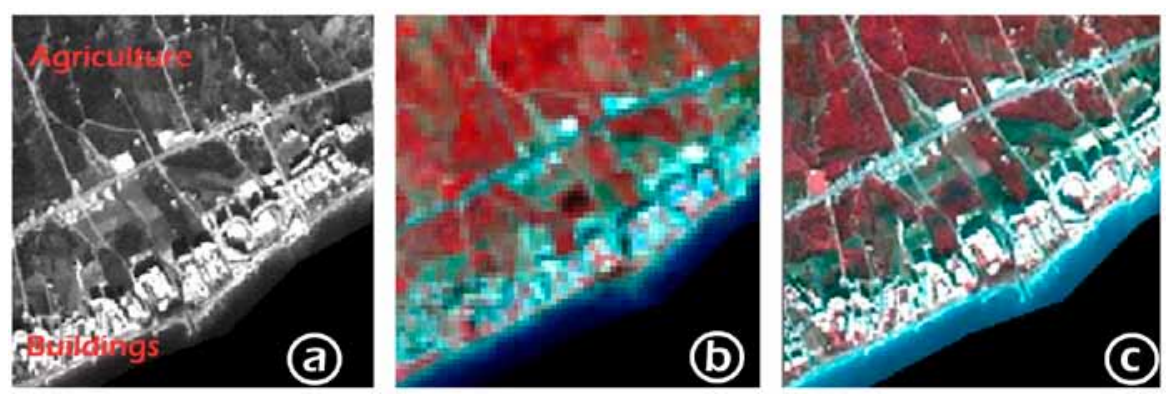

Fig. 2. Examples of merged images that show buildings and agriculture: (a) SPOT

Panchromatic, (b) Landsat TM, (c) merged image

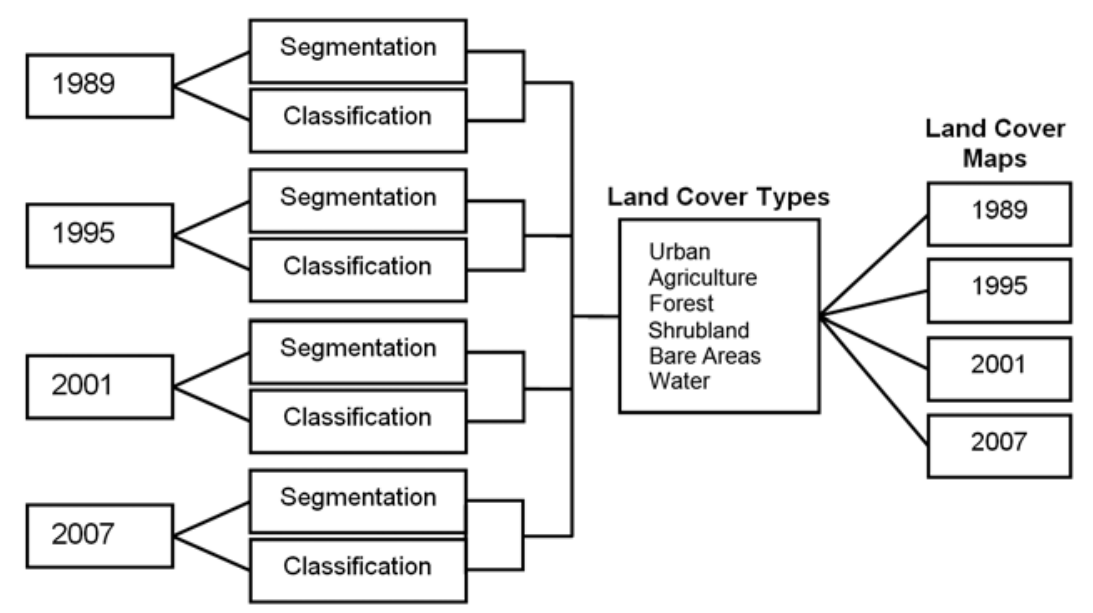

Fig. 3. Flow of the classification procedure 


\subsection{Accuracy assessment}

Accuracies of individual classifications were evaluated in order to validate the results. For this purpose, overall and Kappa accuracies were calculated using reference information that included 256 pixels of reference for each of the individual dates. Stratified random sampling technique was used for selecting reference pixels. Minimum number of sampling points was 16 .

\section{Results and discussion}

\subsection{Land cover mapping}

Images of 1989, 1995, 2001 and 2007 were pre-processed and classified to create land cover maps (Fig. 4).

Resulting maps in Figure 4 were investigated and compared. The most prominent change phenomena in the study area were (1) conversions from/to agriculture areas, and (2) urbanization. Characteristics of these changes can be summarized as follows:

(1) Agriculture-related changes such as agricultural encroachment over natural areas is predominantly observed in N/NW of the study area. As shown in Figure 4, expansion of agriculture over shrubland, resulted in a decrease of this cover type. But more importantly, shrubland cover became more fragmented after 1995. Conversions from agriculture to urban areas were also observed on the coast.
(2) Rapid urbanization is evident in the NE coast of the study area. Figure 4 suggests that these changes are more dramatic between 1989 and 2001.

\subsection{Validating classification results}

The results that indicate the level of consistency between observed (i.e., reference data) and estimated (i.e., land cover maps) land cover is given in Table 1.

Table 1. Accuracies for individual classifications (OA: Overall accuracy (\%); UA: user's accuracy (\%); PA: producer's accuracy (\%); K: Overall Kappa)

\begin{tabular}{lcccccccc}
\hline & \multicolumn{2}{c}{1989} & \multicolumn{2}{c}{1995} & 2001 & \multicolumn{2}{c}{2007} \\
\hline $\begin{array}{l}\text { LU/LC } \\
\text { Type }\end{array}$ & PA & UA & PA & UA & PA & UA & PA & UA \\
\hline Urban & 100 & 94.7 & 74.1 & 100 & 95.0 & 100 & 76.9 & 87.0 \\
\hline $\begin{array}{l}\text { Agri- } \\
\text { culture }\end{array}$ & 99.2 & 97.5 & 99.1 & 94.6 & 99.2 & 91.7 & 93.8 & 95.3 \\
\hline Forest & 100 & 100 & 100 & 93.8 & 100 & 93.8 & 100 & 100 \\
\hline $\begin{array}{l}\text { Shrub- } \\
\text { land }\end{array}$ & 98.4 & 100 & 95.4 & 95.4 & 93.0 & 100 & 93.8 & 95.7 \\
\hline Bare & 90.5 & 100 & 82.6 & 82.6 & 68.0 & 89.5 & 79.0 & 65.2 \\
\hline Water & 100 & 100 & 100 & 95.0 & 100 & 100 & 100 & 90.0 \\
\hline & OA: 94.53 & OA: 94.14 & OA: 94.53 & OA: 91.80 \\
& K: 0.9183 & K: 0.9194 & K: 0.9183 & K: 0.8812 \\
\hline
\end{tabular}

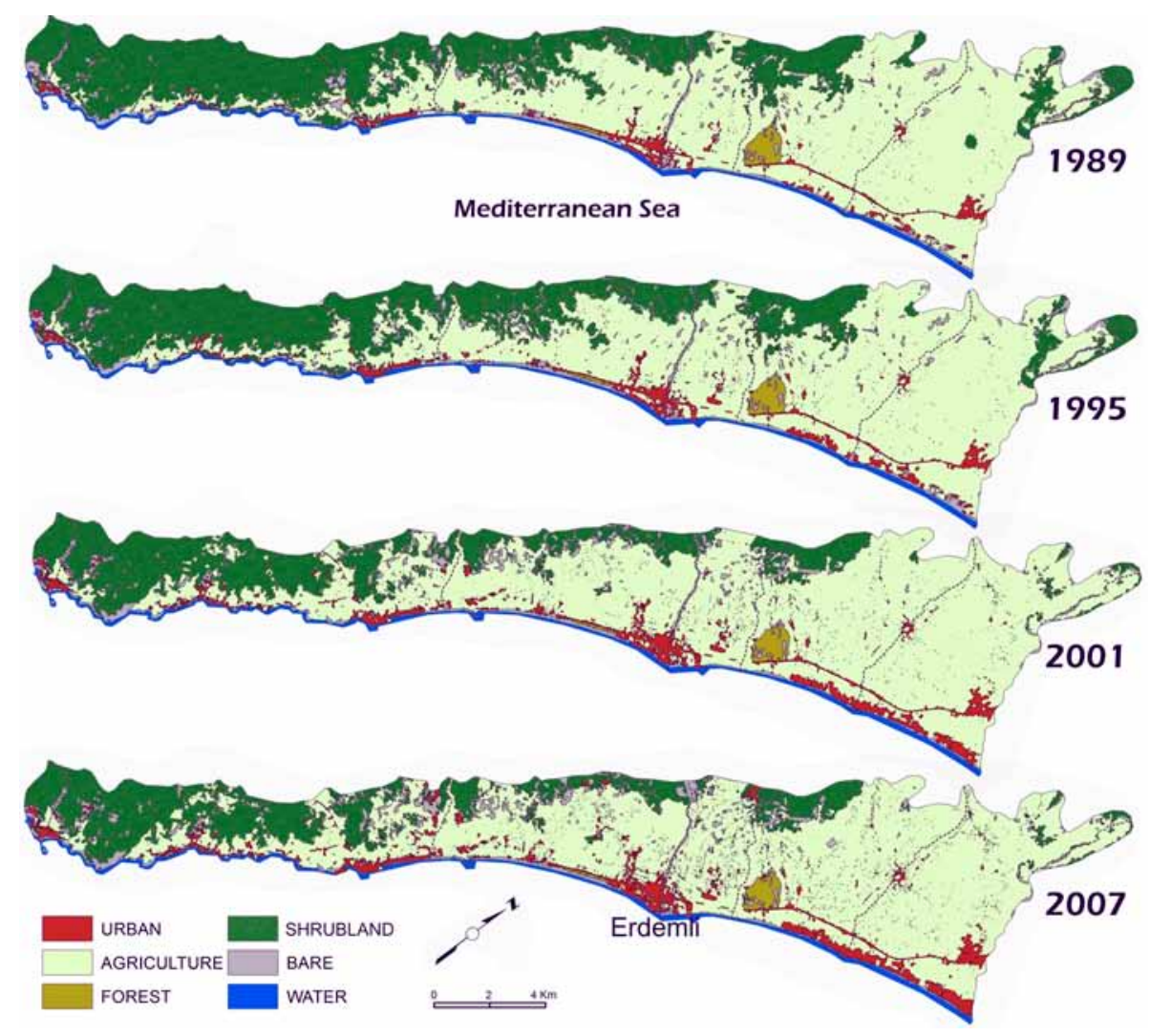

Fig. 4. Changes of LU/LC between 1989 and 2007 
Inspection of the accuracy results showed that overall accuracies and Kappa values were over 90\% in most cases (Table 1). Water surfaces had the highest accuracy values. Accuracy calculations suggested that urban areas were effectively mapped. Accuracies for urban areas in 2007 classification are slightly lower than those for the other dates but still around $90 \%$. Buildings in the study area occur either as small and scattered or relatively larger aggregated patches. These pattern types are highly variable across space and time. High classification accuracies showed that, despite this variation, use of enhanced images provided opportunities for mapping this variability effectively. The fact that an object-based approach was adopted also helped to produce very accurate classifications.

\subsection{Quantifying from-to changes}

Cross tabulations of the earlier and later date LU/LC statistics for three periods (1989-1995, 1995-2001, 20012007) are given in Tables 2, 3 and 4.

Analysis results showed that area coverage of various LU/LC types is disproportionate. Agriculture and shrubland are the most extensive LU/LC types in all time periods. Agriculture covered 8842 ha of land, which made up $57 \%$ of the study area (15378 ha) in 1989. This increased 9994.65 ha in 2007 , corresponding to $65 \%$ of total area. Shrubland cover that occupied 4600 and 2877 ha of land in 1989 and 2007, respectively, has the second largest extent. Bare areas covered 769 ha, almost twice as large as urban coverage (424 ha) in 1989. However, this changed in 2007, due to the facts that urban areas increased almost

Table 2. Quantitative changes in Period 1 (1989-1995)

\begin{tabular}{|c|c|c|c|c|c|c|c|c|}
\hline \multicolumn{9}{|c|}{1995 (ha) } \\
\hline & & Urban & Agriculture & Forest & Shrubland & Bare & Water & Total 1989 \\
\hline \multirow{7}{*}{$\stackrel{\curvearrowright}{\stackrel{2}{二}}$} & Urban & 424.4 & 0.0 & 0.0 & 0.0 & 0.0 & 0.0 & 424.4 \\
\hline & Agriculture & 113.2 & 8761.8 & 0.0 & 2.0 & 22.5 & 0.0 & 8899.4 \\
\hline & Forest & 0.0 & 0.0 & 144.6 & 0.0 & 0.8 & 0.0 & 145.4 \\
\hline & Shrubland & 12.0 & 24.2 & 0.0 & 4587.7 & 31.4 & 0.0 & 4655.4 \\
\hline & Bare & 35.6 & 55.8 & 0.0 & 10.7 & 667.3 & 0.0 & 769.4 \\
\hline & Water & 0.1 & 0.7 & 0.0 & 0.0 & 0.0 & 483.6 & 484.4 \\
\hline & Total 1995 & 585.3 & 8842.4 & 144.6 & 4600.5 & 722.0 & 483.6 & 15378.4 \\
\hline
\end{tabular}

Table 3. Quantitative changes in Period 2 (1995-2001)

\begin{tabular}{|c|c|c|c|c|c|c|c|c|}
\hline \multicolumn{9}{|c|}{2001 (ha) } \\
\hline & & Urban & Agriculture & Forest & Shrubland & Bare & Water & Total 1995 \\
\hline \multirow{7}{*}{ 음 } & Urban & 585.3 & 0.0 & 0.0 & 0.0 & 0.0 & 0.0 & 585.3 \\
\hline & Agriculture & 156.4 & 8612.3 & 0.0 & 0.0 & 73.8 & 0.0 & 8842.4 \\
\hline & Forest & 0.3 & 2.7 & 133.3 & 0.0 & 8.3 & 0.0 & 144.6 \\
\hline & Shrubland & 21.8 & 1234.9 & 0.0 & 3078.4 & 265.3 & 0.0 & 4600.5 \\
\hline & Bare & 64.5 & 240.4 & 0.0 & 0.0 & 417.1 & 0.0 & 722.0 \\
\hline & Water & 0.2 & 0.0 & 0.0 & 0.1 & 0.0 & 483.4 & 483.6 \\
\hline & Total 2001 & 828.5 & 10090.3 & 133.3 & 3078.5 & 764.5 & 483.4 & 15378.4 \\
\hline
\end{tabular}

Table 4. Quantitative changes in Period 3 (2001-2007)

\begin{tabular}{|c|c|c|c|c|c|c|c|c|}
\hline \multicolumn{9}{|c|}{2007 (ha) } \\
\hline & & Urban & Agriculture & Forest & Shrubland & Bare & Water & Total (2001) \\
\hline \multirow{7}{*}{ ঠ్రి } & Urban & 828.5 & 0.0 & 0.0 & 0.0 & 0.0 & 0.0 & 828.5 \\
\hline & Agriculture & 146.5 & 9865.6 & 0.0 & 42.8 & 35.4 & 0.0 & 10090.3 \\
\hline & Forest & 1.5 & 0.3 & 130.5 & 0.0 & 1.0 & 0.0 & 133.3 \\
\hline & Shrubland & 22.4 & 117.1 & 0.0 & 2834.1 & 104.8 & 0.0 & 3078.5 \\
\hline & Bare & 22.8 & 11.6 & 0.0 & 0.0 & 730.1 & 0.0 & 764.5 \\
\hline & Water & 6.3 & 0.0 & 0.0 & 0.0 & 0.0 & 477.1 & 483.4 \\
\hline & Total (2007) & 1028.0 & 9994.7 & 130.5 & 2876.9 & 871.3 & 477.1 & 15378.4 \\
\hline
\end{tabular}


2.5 fold and reached 1028 ha and that bare areas increased at a much slower rate and reached 871 ha.

Cross-tabulations in Tables 2-4 provide information on "from-to" conversions, which showed that most of the changes took place in agricultural and built-up areas. Shrubland and a few patches of pine forest make up the natural vegetation in the study area. Some of these forest patches are included in a natural site. A smaller percentage of forest cover in the coastal zone corresponds to the areas used as camping sites. These areas are strictly protected from building development. Therefore no development occurred in these areas during the study period. Small amount of the change observed in forest areas is outside of the protected locations in upper areas. Conversions from water also exist in cross tabulations. These were mostly due to land reclamation (i.e. land fill) projects on the coast.

As previously mentioned, agriculture-related changes comprised conversions from/to agriculture. Urbanization mostly took place at the expense of agriculture, bare areas and shrubland. Figure 5 shows change trends in the forms of conversions "from agriculture" and "to urban" areas.

As shown in Figure 5, urbanization on agriculture areas (i.e. conversions from agriculture to urban areas) exists in all periods. Although highest amount of this type of change is observed in Period 2 (1995-2001), it persisted in Period 3 (2001-2007) at similar rates. The fact that higher rates of urbanization takes place on agriculture areas is an important finding worthy of consideration and it requires attention in development planning for the region.
Other changes depicted in Figure 5, such as those from agriculture to shrubland and bare areas also increased. High rates of conversions from agriculture to bare areas in Period 2 should be interpreted carefully owing to the fact that seasonality impacted map comparisons (e.g., 1989-1995, 1995-2001, etc.) differently. Change detection for the Periods 1 and 3 were based on the comparisons of winter and early summer images. However, Period 2 was assessed using early summer images for both the earlier and later dates. This did not cause any particular problem during classifications except for the case of open-field agriculture that show contrasting spectral responses between seasons due to presence (or absence) of crops. As a result, some agriculture fields without crops were classified as bare areas. These locations appeared as agriculture-to-bare (or vice versa) conversions in winter-summer comparisons. Therefore, conversion between agriculture and bare areas is affected by seasonality. In some locations, even the comparisons of the same seasons suffered from confusion between agriculture and bare areas due to different crop types (e.g. different harvest times) or changes between annual and permanent crops over time.

In the light of above given explanations one may expect that agriculture-to-bare conversions in Figure 5 (left) may be less than estimated, since a proportion of this type of conversion is actually agriculture-to-agriculture (i.e., cropsto-bare soil after harvest) conversions. On the other hand, bare-to-urban conversions in Figure 5 (right) may be interpreted that a certain amount of bare areas in this conversion type is in fact agriculture. These suggest that destruction of
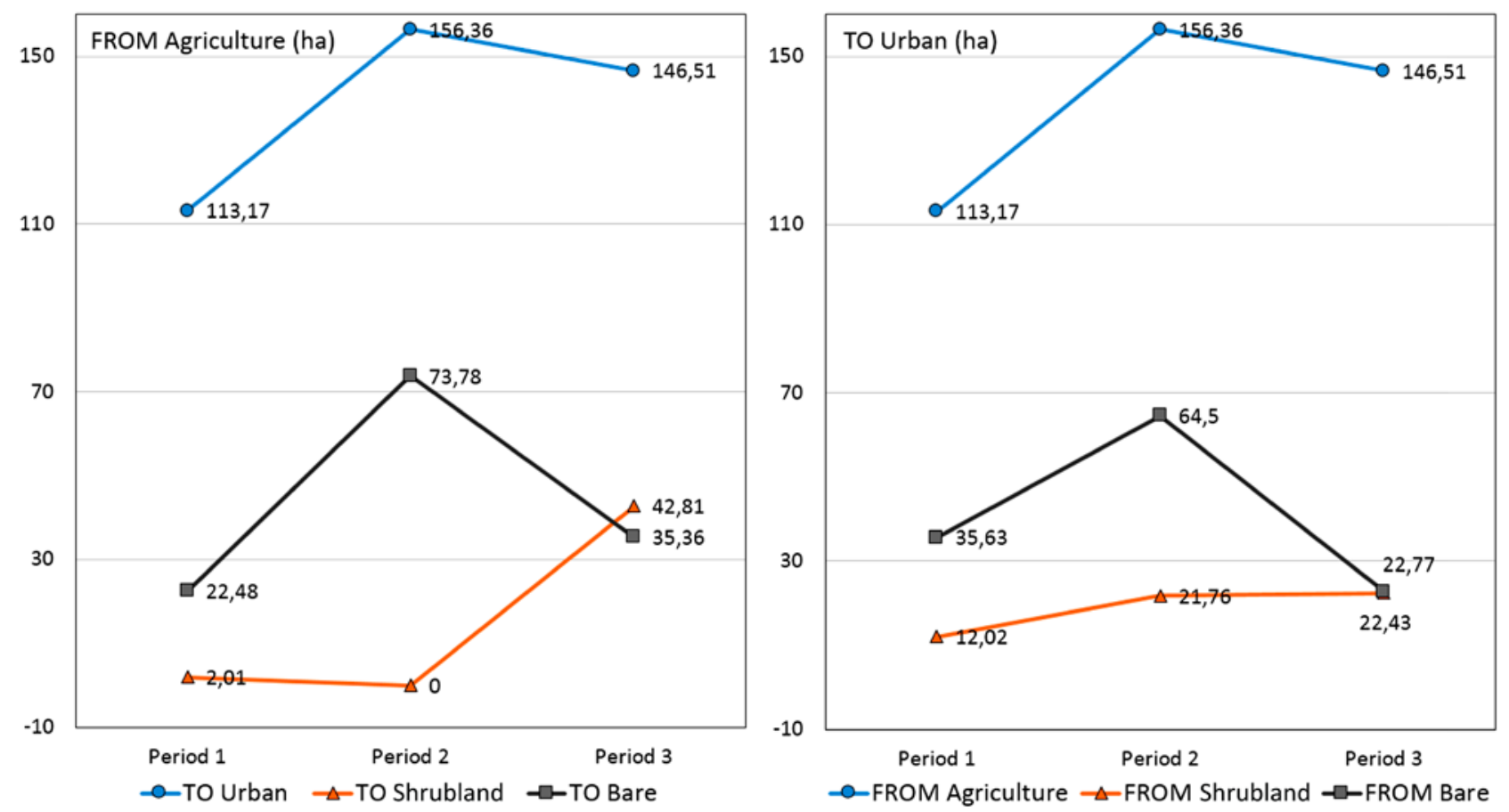

Fig. 5. Agriculture- and urban-related conversion trends across three time periods 
agriculture areas by urbanization is even higher than calculated values due to overestimation of bare areas.

Conversion from agriculture to shrubland is due to land abandonment especially in upper areas, where limestone outcrops and patches of natural vegetation exist. Increasing amounts of conversions from shrubland to urban in Figure 5 (right) is the evidence that urbanization tends to grow in the west of the area, where shrubland dominates the landscape.

Alphan, Yilmaz (2005) reported that agriculture has increasingly grown over marginal areas and urban development occurred at the expense of prime croplands in the eastern Mediterranean coast of Turkey. Other parts of the Turkish Mediterranean coast such as Kusadasi and Edremit bay faced similar problems resulting from development (Kara et al. 2013; Irtem et al. 2005). Intense human uses also cause complex LU/LC changes around the Mediterranean basin (Salvati, Sabbi 2011). The analyses showed that study area is no exception in terms of diversity of the LU/LC and the magnitude of its change. Tourism is one of the main drivers for development on the coast. One of the easily recognizable impacts of building development on the coast is the change of visibility in coastal landscapes (Alphan, Sonmez 2015; Musaoglu et al. 2004). However, many other direct or indirect impacts such as those that are caused by land-based pollutants carried into the Mediterranean coastal zone also exist. Building development on the coast consume prime soils and it pushes agriculture towards marginal areas. This process is an important cause of agricultural intensification that may lead to biodiversity losses (Pekin 2013). Residential and touristic development is considered one of the key conservation challenges in Turkey. Significant conservation efforts have focused on protecting the species' nesting sites (Sekercioglu et al. 2011). Areas designated as archaeological and natural sites contribute to protecting important coastal areas from development. Analysis results in this study showed that such designations helped to protect coast from development. As it can clearly be seen in Figure 4, east coast of the town of Erdemli, which is a natural site, remained intact (i.e., no urban development between 1989 and 2007).

Despite the fact that several protection statuses control building development on the coast, development over unprotected coastal areas is still an important issue. Integrated management of coastal landscape requires a comprehensive inventory of biophysical features, landscape patterns and processes. Prem (2007) described main concepts and approaches of landscape management. Vulnerability analysis, landscape character assessment, modelling and simulation of change were described as some important topics for management. However, in absence of comprehensive information, priority areas may be determined using the areas of likely development suggested by future development models.
Several authors used remotely sensed images for landscape mapping and bi-temporal change detection purposes in coastal landscapes. For example, CORONAASTER or Landsat TM-ASTER image pairs were classified and compared (Hepcan 2013; Kesgin, Nurlu 2009) for change detection. However, this study used merged images with $10 \mathrm{~m}$ spatial resolution in order to maximize consistency between images and minimize possible classification and change detection errors due to resolution difference.

\section{Conclusion}

This paper dealt with tourism-oriented building development and LU/LC changes in a coastal zone, where land morphology and human preferences resulted with linear development with a scattered pattern of buildings. The need for higher resolution of spatial information that arises from spatial characteristics of this development made it necessary to employ image enhancement techniques. Therefore, SPOT panchromatic and Landsat images were integrated prior to image analyses (i.e., image classification and change detection).

Selection of seasonally consistent images is an important criterion for change detection in order to reduce potential negative impacts of different variables such as vegetation phenology, crop pattern, snow cover and soil wetness on image processing. However, it becomes increasingly difficult as a longer time span that includes more than two images is selected for change analyses.

Mapping the state of the LU/LC in this coastal zone in 1980's is of critical importance to effectively demonstrate magnitude and extent of change in 1980's due to the fact that integration of the country's economy into expanding world economy caused serious landscape-level environmental changes in this period. Therefore, an 18-year period between 1989 and 2007 was used in change detection to cover 1980's in change analyses. Time series included four images that are 6 years apart. In fact, the start of this period was the earliest available date for SPOT (panchromatic) imagery.

Images of the start and end dates of the 18-year study period are winter images, while other two images were early-summer images. For this reason, post-classification comparison approach was adopted for change detection. Unlike pre-classification, this approach relies on individual image classifications and pairwise comparisons. This approach eliminates difficulties arising from sensor differences or environmental variability, since every image is classified independently. However, some confusion between agriculture and bare areas still existed.

This paper demonstrated that urban, agriculture and shrublands changed rapidly in the Eastern Mediterranean coast of Turkey. Spatial configuration of LU/LC suggests that urban patches are likely to grow on agriculture areas. 
It also shows that possible expansion of agriculture will take place over shrublands. As depicted in the LU/LC maps, shrublands became fragmented between 1989 and 2007. They may become even more fragmented due to agricultural expansion that creates important implications for biodiversity and wildlife. Development scenarios may be modelled and possible development areas can be taken as priority areas for further analyses in order to identify and protect valuable resources and contribute to sustainable management.

This paper used a methodology for analysing change trends resulting from development on the coast with spatially enhanced images. As demonstrated in this paper, SPOT panchromatic images can be incorporated with Landsat datasets to take the advantages of high spatial and spectral resolution in a single image dataset. Spatially enhanced images were successful for mapping the extent of developed areas and the other LU/LC types. The quantitative information derived from image classifications and change detection can be used as inputs for modelling future development and help to create development planning and resource management solutions.

\section{Acknowledgments}

This work was supported by Turkish Scientific and Technological Research Council (TUBITAK) under the grant number CAYDAG 111Y253.

\section{References}

Ahmad, R.; Singh, R. P. 2002. Comparison of various data fusion for surface features extraction using IRS PAN and LISS-III data, Land Surface Characterization and Remote Sensing of Ocean Processes 29(1): 73-78.

http://dx.doi.org/10.1016/s0273-1177(01)00631-7

Aiazzi, B.; Alparone, L.; Baronti, S.; Carla, R. 1996. A pyramid approach to fusion of landsat TM and SPOT-PAN data to yield multispectral high-resolution images for environmental archaeology, Remote Sensing for Geography, Geology, Land Planning, and Cultural Heritage 2960: 153-162. http://dx.doi.org/10.1117/12.262459

Alberti, M.; Weeks, R.; Coe, S. 2004. Urban land-cover change analysis in Central Puget Sound, Photogrammetric Engineering and Remote Sensing 70(9): 1043-1052. http://dx.doi.org/10.14358/PERS.70.9.1043

Alphan, H. 2005. Perceptions of coastline changes in river deltas: southeast Mediterranean coast of Turkey, International Journal of Environment and Pollution 23(1): 92-102.

http://dx.doi.org/10.1504/IJEP.2005.006398

Alphan, H.; Derse, M. A. 2013. Change detection in Southern Turkey using normalized difference vegetation index (NDVI), Journal of Environmental Engineering and Landscape Management 21(1): 12-18.

http://dx.doi.org/10.3846/16486897.2012.663091

Alphan, H.; Sonmez, F. 2015. Mapping availability of sea view for potential building development areas, Environmental Monitoring and Assessment 187(7).
Alphan, H.; Yilmaz, K. T. 2005. Monitoring environmental changes in the Mediterranean coastal landscape: The case of Cukurova, Turkey, Environmental Management 35(5): 607619. http://dx.doi.org/10.1007/s00267-004-0222-7

Ayazli, I. E.; Batuk, F.; Kleinschmit, B. 2010. Simulating landuse changes driven by a third bosphorus bridge, in Special Joint Symposium of ISPRS Technical Commission IV \& AutoCartoin conjunction with ASPRS/CaGIS 2010 Fall Specialty Conference, 15-19 November 2010, Orlando, Florida.

Chang, N. B.; Han, M.; Yao, W.; Chen, L. C.; Xu, S. G. 2010. Change detection of land use and land cover in an urban region with SPOT-5 images and partial Lanczos extreme learning machine, Journal of Applied Remote Sensing 4.

Chavez, P. S.; Sides, S. C.; Anderson, J. A. 1991. Comparison of 3 different methods to merge multiresolution and multispectral data-landsat TM and SPOT panchromatic, Photogrammetric Engineering and Remote Sensing 57(3): 295-303.

Deng, J. S.; Wang, K.; Li, J.; Feng, X. L.; Huang, J. Q. 2005. Integration of SPOT-5 and ETM+ images to detect land cover change in urban environment, in IGARSS 2005: IEEE International Geoscience and Remote Sensing Symposium, 25-29 July 2005, Seoul, Korea. Vols 1-8, Proceedings, 2284-2286.

Desalegn, T.; Cruz, F.; Kindu, M.; Turrión, M. B.; Gonzalo, J. 2014. Land-use/land-cover (LULC) change and socioeconomic conditions of local community in the central highlands of Ethiopia, International Journal of Sustainable Development \& World Ecology 21(5): 406-413.

Eastman, J. R. 2012. IDRISI Selva Manual. Manual Version 17.01. Clark Labs, Clark University. 324 p.

Erdas. 1999. Field guide, revised and expanded. $5^{\text {th }}$ ed. Atlanta, Georgia: ERDAS, Inc. 672 p.

Fang, H.; Xu, Y.; Ye, Z.; Zhang, Z.; Pan, S.; Deng, L.; Luo, Z.; Chen, S. 2014. Impact of urbanization on nutrients and heavy metal pollution of Napahai Wetland, Shangri-La County, China, International Journal of Sustainable Development \& World Ecology 22(2): 117-126. http://dx.doi.org/10.1080/13504509.2014.918908

He, C. Y.; Wei, A. N.; Shi, P. J.; Zhang, Q. F.; Zhao, Y. Y. 2011. Detecting land-use/land-cover change in rural-urban fringe areas using extended change-vector analysis, International Journal of Applied Earth Observation and Geoinformation 13(4): 572-585. http://dx.doi.org/10.1016/j.jag.2011.03.002

Hepcan, C. C.; 2013. Quantifying landscape pattern and connectivity in a Mediterranean coastal settlement: the case of the Urla district, Turkey, Environmental Monitoring and Assessment 185(1): 143-155. http://dx.doi.org/10.1007/s10661-012-2539-7

Hosomura, T.; Katho, K. 1998. Optical image data fusion by using intensity operation on HIS transformation, in Igarss '98-1998 International Geoscience and Remote Sensing Symposium, 6-10 July 1998, Seattle, WA, USA. Proceedings Vols 1-5, 1318-1319.

Irtem, E.; Kabdasli, S.; Azbar, N.; 2005. Coastal zone problems and environmental strategies to be implemented at Edremit Bay, Turkey, Environmental Management 36(1): 37-47. http://dx.doi.org/10.1007/s00267-004-0062-5

Kamh, S.; Ashmawy, M.; Kilias, A.; Christaras, B. 2012. Evaluating urban land cover change in the Hurghada area, Egypt, by using GIS and remote sensing, International Journal of Remote Sensing 33(1): 41-68. http://dx.doi.org/10.1080/01431161.2010.550331 
Kara, B.; Esbah, H.; Deniz, B. 2013. Monitoring and analyzing land use/land cover changes in a developing coastal town: a case study of Kusadasi, Turkey, Journal of Coastal Research 29(6): 1361-1372.

http://dx.doi.org/10.2112/JCOASTRES-D-11-00140.1

Kesgin, B.; Nurlu, E. 2009. Land cover changes on the coastal zone of Candarli Bay, Turkey using remotely sensed data, Environmental Monitoring and Assessment 157(1-4): 89-96. http://dx.doi.org/10.1007/s10661-008-0517-x

Kowe, P.; Pedzisai, E.; Gumindoga, W.; Rwasoka, D. T. 2015. An analysis of changes in the urban landscape composition and configuration in the Sancaktepe District of Istanbul Metropolitan City, Turkey using landscape metrics and satellite data, Geocarto International 30(5): 506-519.

http://dx.doi.org/10.1080/10106049.2014.905638

Liu, T.; Yang, X. J. 2015. Monitoring land changes in an urban area using satellite imagery, GIS and landscape metrics, $A p$ plied Geography 56: 42-54.

http://dx.doi.org/10.1016/j.apgeog.2014.10.002

Merlotto, A.; Piccolo, M. C.; Bertola, G. R. 2012. Urban growth and land use/cover change at Necochea and Quequen cities, Buenos Aires province, Argentina, Revista De Geografia Norte Grande 53: 159-176.

http://dx.doi.org/10.4067/S0718-34022012000300010

Miralles i Garcia, J. L. 2007. The introduction of the sustainability in the procedures regulated for urban planning: the case of the last act on urbanism, territory and landscape in the Valencian Community (Spain), Sustainable Development and Planning III 102(1-2): 505-513.

http://dx.doi.org/10.2495/sdp070482

Musaoglu, N.; Seker, D. Z.; Kabdasli, S.; Kaya, S.; \& Duran, Z. 2004. Using remote sensing and GIS for the assessment of visual attributes: a case study of the south coastal zone of Turkey, Fresenius Environmental Bulletin 13(9): 854-859.

Nunez, J.; Otazu, X.; Fors, O.; Prades, A.; Pala, V.; Arbiol, R. 1999. Image fusion with additive multiresolution wavelet decomposition. Applications to SPOT plus Landsat images, Journal of the Optical Society of America a-Optics Image Science and Vision 16(3): 467-474.

http://dx.doi.org/10.1364/JOSAA.16.000467

Nunez, J.; Otazu, X.; Fors, O.; Prades, A.; Pala, V.; Arbiol, R. 1998. Data fusion of SPOT and LANDSAT images using additive multiresolution wavelet decomposition, Image and Signal Processing for Remote Sensing 4(3500): 202-213. http://dx.doi.org/10.1117/12.331865

Pekin, B. K. 2013. Effect of widespread agricultural chemical use on butterfly diversity across Turkish provinces, Conservation Biology 27(6): 1439-1448.

http://dx.doi.org/10.1111/cobi.12103

Prem, M. 2007. Landscape management in the Mediterranean, in Medcoast 07: Eighth International Conference on the Mediterranean Coastal Environment, 13-17 November 2007, Alexandria, Egypt 211-222.

Ramachandra, T. V. Bharath, S.; Bharath, A. 2014. Spatio-temporal dynamics along the terrain gradient of diverse landscape, Journal of Environmental Engineering and Landscape Management 22(1): 50-63. http://dx.doi.org/10.3846/16486897.2013.808639

Salvati, L.; \& Sabbi, A. 2011. Exploring long-term land cover changes in an urban region of southern Europe, International Journal of Sustainable Development and World Ecology 18(4): 273-282. http://dx.doi.org/10.1080/13504509.2011.560453
Sancar, C.; Turan, S.O.; Kadiogullari, A. L. 2009. Land use-cover change processes in Urban fringe areas: Trabzon case study, Turkey, Scientific Research and Essays 4(12): 1454-1462.

Sarp, G. 2014. Spectral and spatial quality analysis of pan-sharpening algorithms: A case study in Istanbul, European Journal of Remote Sensing 47: 19-28.

http://dx.doi.org/10.5721/EuJRS20144702

Schneider, A. 2012. Monitoring land cover change in urban and pen-urban areas using dense time stacks of Landsat satellite data and a data mining approach, Remote Sensing of Environment 124: 689-704.

http://dx.doi.org/10.1016/j.rse.2012.06.006

Sekercioglu, C. H.; Anderson, S.; Akcay, E.; Bilgin, R.; Can, O. E.; Semiz, G.; et al. 2011. Turkey's globally important biodiversity in crisis, Biological Conservation 144(12): 2752-2769. http://dx.doi.org/10.1016/j.biocon.2011.06.025

Shaban, M. A.; Dikshit, O. 2002. Evaluation of the merging of SPOT multispectral and panchromatic data for classification of an urban environment, International Journal of Remote Sensing 23(2): 249-262.

http://dx.doi.org/10.1080/01431160010007088

Smiraglia, D.; Rinaldo, S.; Ceccarelli, T.; Bajocco, S.; Salvati, L.; Ricotta, C.; Perin, L. 2014. A cost-effective approach for improving the quality of soil sealing change detection from Landsat imagery, European Journal of Remote Sensing 47: 805-819. http://dx.doi.org/10.5721/EuJRS20144746

Stefanov, W. L.; Ramsey, M. S.; Christensen, P. R. 2001. Monitoring urban land cover change: An expert system approach to land cover classification of semiarid to arid urban centers, Remote Sensing of Environment 77(2): 173-185. http://dx.doi.org/10.1016/S0034-4257(01)00204-8

Taubenbock, H.; Esch, T.; Felbier, A.; Wiesner, M.; Roth, A.; Dech, S.; 2012. Monitoring urbanization in mega cities from space, Remote Sensing of Environment 117: 162-176. http://dx.doi.org/10.1016/j.rse.2011.09.015

Villa, P.; Boschetti, M.; Bianchini, F.; Cella, F. 2012. A hybrid multi-step approach for urban area mapping in the Province of Milan, Italy, European Journal of Remote Sensing 45(2): 333-347. http://dx.doi.org/10.5721/EuJRS20124529

Walker, R. 2001. Urban sprawl and natural areas encroachment: linking land cover change and economic development in the Florida Everglades, Ecological Economics 37(3): 357-369. http://dx.doi.org/10.1016/S0921-8009(01)00178-1

Welch, R.; Ehlers, W. 1987. Merging multiresolution SPOT HRV and Landsat TM data, Photogrammetric Engineering \& Remote Sensing 53(3): 301-303.

Wu, Y.; Li, M.; Liao, G. S. 2004. Multiresolution wavelet decomposition to merge Landsat TM and SPOT panchromatic data, in $3 r d$ International Conference on Computational Electromagnetics and Its Applications, 1-4 November 2004, Beijing, China.

Xian, G.; Homer, C.; Bunde, B.; Danielson, P.; Dewitz, J.; Fry, J.; $\mathrm{Pu}, \mathrm{R}$. L. 2012. Quantifying urban land cover change between 2001 and 2006 in the Gulf of Mexico region, Geocarto International 27(6): 479-497. http://dx.doi.org/10.1080/10106049.2011.652675

Yang, L. M.; Xian, G.; Klaver, J. M.; Deal, B. 2003. Urban landcover change detection through sub-pixel imperviousness mapping using remotely sensed data, Photogrammetric Engineering and Remote Sensing 69(9): 1003-1010. http://dx.doi.org/10.14358/PERS.69.9.1003 
Yiran, G. A. B.; Kusimi, J. M.; Kufogbe, S. K. 2012. A synthesis of remote sensing and local knowledge approaches in land degradation assessment in the Bawku East District, Ghana, International Journal of Applied Earth Observation and Geoinformation 14(1): 204-213.

http://dx.doi.org/10.1016/j.jag.2011.09.016

Yu, X. Y.; Zhang, A. D.; Hou, X. Y.; Li, M. J.; Xia, Y. X. 2013. Multi-temporal remote sensing of land cover change and urban sprawl in the coastal city of Yantai, China, International Journal of Digital Earth 6: 137-154.

Zhang, F. T.; Zhang, J. Y.; Shao, J. X. 2014. Karst urban land use/ cover change research - in Guiyang city as an example, Environmental Engineering 1-4(864-867): 2764-2767.
Zhang, P.; Tang, C.; MA, S.; Yuan, H.; Gao, H.; Fan, W. 2011. Using Markov chains to analyze changes in wetland trends in arid Yinchuan Plain, China, Mathematical and Computer Modelling 54(3-4): 924-930. http://dx.doi.org/10.1016/j.mcm.2010.11.017

Zhou, J.; Civco, D. L.; Silander, J. A. 1998. A wavelet transform method to merge landsat TM and SPOT panchromatic data, International Journal of Remote Sensing 19(4): 743-757. http://dx.doi.org/10.1080/014311698215973

Hakan ALPHAN. Dr, Professor at the Department of Landscape Architecture, Faculty of Agriculture, Cukurova University, Turkey. He gained his Landscape Architecture Ph.D. in 2004 from the Institute of Science, Cukurova University, Turkey. Publications: Author/co-author of over 60 scientific publications, including peer-reviewed journal papers, book chapters and papers in conference proceedings. Research interests: remote sensing and GIS, landscape-level environmental monitoring, change detection, landscape pattern and environmental processes.

Laden GÜVENSOY. She gained her M.Sc. from Institute of Science, Department of Landscape Architecture, Cukurova University, Turkey in 2014. Research interests: remote sensing and GIS. 